\title{
Sea water surface energy balance in the Arctic fjord (Hornsund, SW Spitsbergen) in May-November 2014
}

\author{
Krzysztof Fortuniak ${ }^{1}$ - Rajmund Przybylak ${ }^{2}$ - Andrzej Araźny ${ }^{2}$. \\ Włodzimierz Pawlak ${ }^{1}$ Przemysław Wyszyński ${ }^{2}$
}

Received: 24 September 2015 / Accepted: 5 February 2016/Published online: 18 February 2016

(C) The Author(s) 2016. This article is published with open access at Springerlink.com

\begin{abstract}
The full surface energy balance of the sea water of the Arctic fjord was analysed for the period from May to November 2014 in Hornsund (SW Spitsbergen). The sensible and latent turbulent fluxes were measured with the aid of the open-path eddy covariance method. The measurement site was located in the Wilczek Peninsula (Wilczekodden) on the rocks, right at the seafront. At this location, and with the wind system observed there, the source area of turbulent fluxes was spread over the sea water of the Hornsundfjord. The turbulent fluxes were calculated for 1-h intervals with a standard methodology. Stationarity was checked by three independent tests, and two datasets were analysed independently: data approved by all three tests, and data approved by at least one of the tests. The sensible heat flux, $Q_{H}$, undergoes a clear seasonal regularity, with downward heat transport (negative fluxes) from July to September (with mean ranges from -30 to $-15 \mathrm{Wm}^{-2}$ ), reaching close to zero in October, then upward in the other months of the analysed period, reaching maximum in November $\left(50 \mathrm{Wm}^{-2}\right)$. The latent heat flux, $Q_{E}$, was mostly positive (more than $90 \%$ ) and more intensive. The highest mean values of $Q_{E}$ were recorded in July and November (around $135 \mathrm{Wm}^{-2}$ ), with the lowest in May, June and August (around $70 \mathrm{Wm}^{-2}$ ). Very intensive latent heat fluxes,
\end{abstract}

Krzysztof Fortuniak

kfortun@uni.lodz.pl

1 Department of Meteorology and Climatology, Faculty of Geographical Science, University of Łódź, Narutowicza 88 str, 90-139 Łódź, Poland

2 Department of Meteorology and Climatology, Faculty of Earth Sciences, Nicolaus Copernicus University, Lwowska 1 str, 87-100 Toruń, Poland above $200 \mathrm{Wm}^{-2}$, in extreme cases exceeding $500 \mathrm{Wm}^{-2}$, were observed in all months.

\section{Motivation}

The Arctic fjords can be considered to be transition zones between land and ocean. In spite of the increasing amount of investigation into the Arctic climate, the surface-atmosphere exchange processes are poorly recognized in this complex environment. Knowledge of these processes is important not only to improving weather forecasts for the area but also to our understanding of the deep-water formation in the fjords (Skogseth et al. 2008) and, in consequence, of global ocean circulation (Mäkiranta et al. 2011). The energy and momentum exchange between air and sea water in fjords is complicated due to many factors altering the local wind field and the specific properties of a fjord's water. The winds are modified by the topography, and the local flows forced by the thermal properties of the surface (e.g. katabatic winds down the glaciers, foehns) (Argentini et al. 2003; Kilpeläinen and Sjöblom 2010). The local topography, roughness and surface physical properties all undergo a seasonal cycle in Arctic fjords due to snow and ice accumulation and the glaciers' variability. The properties of sea water in the fjords are modified by melted fresh water and can change rapidly during a glacier's calving, while the extreme temperature difference between the water and the atmosphere can lead to large heat fluxes in ice-free areas (Kilpeläinen and Sjöblom 2010). Furthermore, the conditions over land-fast fjord ice also differ from those over pack ice in the ocean (Mäkiranta et al. 2011). Ultimately, all these factors contribute to a specific energy balance in the Arctic fjords. The quantification of this energy balance's components, particularly turbulent fluxes, still remains a challenging task in such environments and available empirical data are 
unique. The turbulent fluxes could be estimated in different ways. It is generally accepted that the eddy covariance method is the most suitable, direct method of determining turbulent components of surface energy balance. This method gives accuracy and temporal resolution unachievable by alternative techniques. Its potential in Arctic regions has been demonstrated in a number of studies (e.g. McFadden et al. 1998; Oechel et al. 1998), but the extreme environmental conditions and attendant logistical difficulties limit the number of available data. One of the most complex analyses of the turbulent exchange over the sea ice was made as part of the SHEBA experiment (Uttal et al. 2002; Pinto et al. 2003; Grachev et al. 2005, 2007, 2008; Mirocha et al. 2005), in which the atmospheric boundary layer and the surface energy balance were studied over the Arctic pack ice for a whole year. Other studies have been conducted on Svalbard (Harding and Lloyd 1998; Lüers and Bareiss 2011; Westermann et al. 2009; Mäkiranta et al. 2011). Additionally, Kilpeläinen and Sjöblom (2010) described the exchange of momentum and sensible heat in an Arctic fjord system on Spitsbergen, Svalbard (Norway) during spring 2008. An extension of these studies to the summer seasons of 2008-2010 was recently presented by Kral et al. (2014). However, only the sensible heat flux and momentum transfer were measured with the eddy covariance method in these studies. Comparing different observation techniques for the estimation of atmospheric turbulent fluxes of momentum and sensible heat (the gradient method, the bulk method and the eddy covariance method), Sjöblom (2014) pointed to the need for more observation in the Arctic. On a larger scale, the computations for the latent and sensible heat fluxes based on bulk formulas show extremely strong wintertime heat fluxes in the northern Greenland Sea, with the highest monthly average net fluxes well over $400 \mathrm{Wm}^{-2}$ in the Barents Sea (Häkkinen and Cavalieri 1989).

Hereafter, we present the results of the eddy covariance measurements of both sensible and latent turbulent heat fluxes, together with the radiation components, for an Arctic fjord. The measurements were made from May to November 2014 in Hornsund (SW Spitsbergen). The system was installed on a rocky cape close to the water, in such a way as to allow for study of the heat balance above the sea water of the Hornsundfjord. The main aim was to recognize the range of turbulent heat fluxes and radiation balance in the area where the surface energy exchange is complicated by strong modification of thermal and humidity contrasts, rapid changes of sea water properties due to glacial calving, flow modification due to fjord topography, and by the possible influences of local winds such as foehns and bora.

\section{Measurement site and instrumentation}

The site chosen for measurement of the heat balance was located in the area of the Polish Polar Station, in the northern part of Hornsundfjord (SW Spitsbergen) (Fig. 1). Its geographical coordinates were $\varphi=77^{\circ} 00^{\prime} \mathrm{N}, \lambda=15^{\circ} 33^{\prime} \mathrm{E}$.

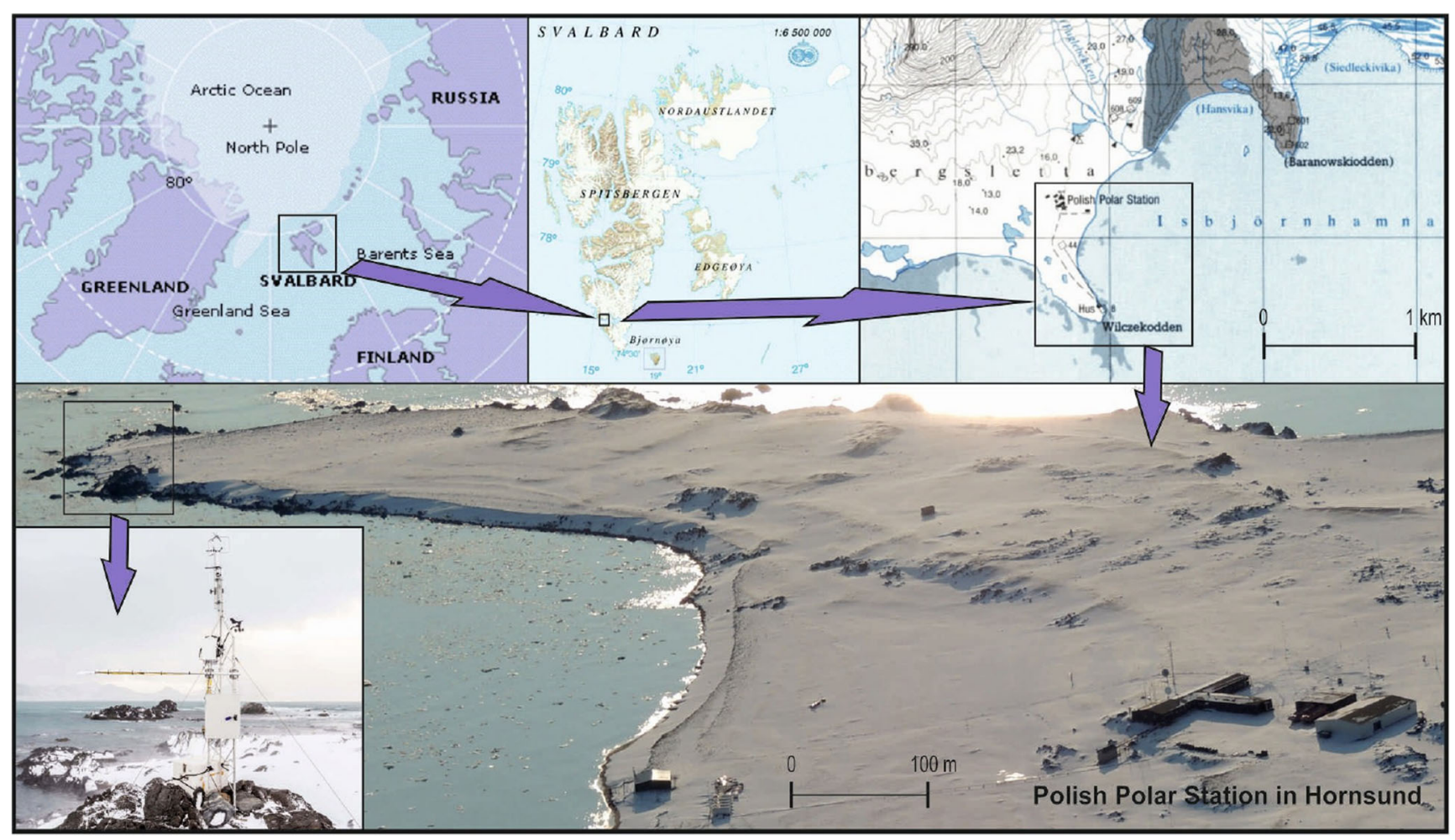

Fig. 1 Location of measuring site in the Wilczek Peninsula (Hornsund, SW Spitsbergen) 
Observations began there on May 1, 2014, and ended at the end of November. Hornsundfjord runs latitudinally from east to west. Its width in the region of the measurement site is about $10 \mathrm{~km}$, with a length of about $30 \mathrm{~km}$. The thermal privilege of this region, as well as the entire Spitsbergen, is markedly seen, and particularly in winter when the main factors controlling air temperature are atmospheric and oceanic circulation (Przybylak 2002; Bednorz 2011). As a result, this area is about $20^{\circ} \mathrm{C}$ warmer than the north-eastern part of the Canadian Arctic, lying at the same latitude (Przybylak 2003). Mean annual air temperature at the Hornsund meteorological station in $1979-2009$ was equal to $-4.3{ }^{\circ} \mathrm{C}$, while its monthly values varied from $-10.9{ }^{\circ} \mathrm{C}$ in January to $4.4{ }^{\circ} \mathrm{C}$ in July (Marsz 2013). Mean annual total precipitation in the same period was $434.4 \mathrm{~mm}$ (Lupikasza 2013). For our measurements, the eddy covariance system (EC) was installed on top of a thin mast at a height of $11 \mathrm{~m}$ above sea level (Fig. 1). The mast was fixed to a rock on the southern promontory of the Wilczek Peninsula (Wilczekodden), which is a 500-m-long cape west of Isbjørnhamna, on the northern side of Hornsund's mouth. The katabatic flows from the Hansbreen glacier, which approaches the sea near Isbjørnhamna approximately $2.5 \mathrm{~km}$ east of the measurement site and the fjord topography, acts to modify the local wind field, and determines the prevailing eastern winds in the area of the investigations. As a result, the source area of turbulent sensors extends approximately $1 \mathrm{~km}$ east into the Isbjørnhamna bay (Fig. 2).

The eddy covariance system included a sonic anemometer (81000, RM Young, USA) and a krypton hygrometer (KH20, Campbell Sci., USA) connected to the data logger (CR3000, Campbell Sci., USA). The krypton hygrometer was manually cleaned every day with distilled water to remove dirt and salt particles from the transmitters. The fast-response data were collected at $10 \mathrm{~Hz}$ frequency and stored in 15-min files on external Compact Flash cards. The additional slow-response data were collected for other energy balance components and reference meteorological data. The components of radiation balance including downward and upward and longwave and shortwave $\left(L_{d}, L_{u}, K_{d}\right.$ and $K_{u}$, respectively) were independently measured by a net radiometer (CNR4, Kipp \& Zonen, Holland). The four-component net radiometer consisted of two independently calibrated pyrgeometers and two pyranometers, placed face up and face down. The radiometer allowed for calculation of radiation balance as $Q^{*}=K_{d}-K_{u}+$ $L_{d}-L_{u}$. The CNR4 was also equipped with a Pt-100 temperature sensor used for corrections of longwave radiation values. The instruments were unventilated, so they were cleaned every 3 days with an alcohol solution to clear off dirt, atmospheric pollutants and precipitation on their domes. The sensors of the CNR4 were mounted on an extension arm to measure radiation fluxes from above water, rather than the rocky base

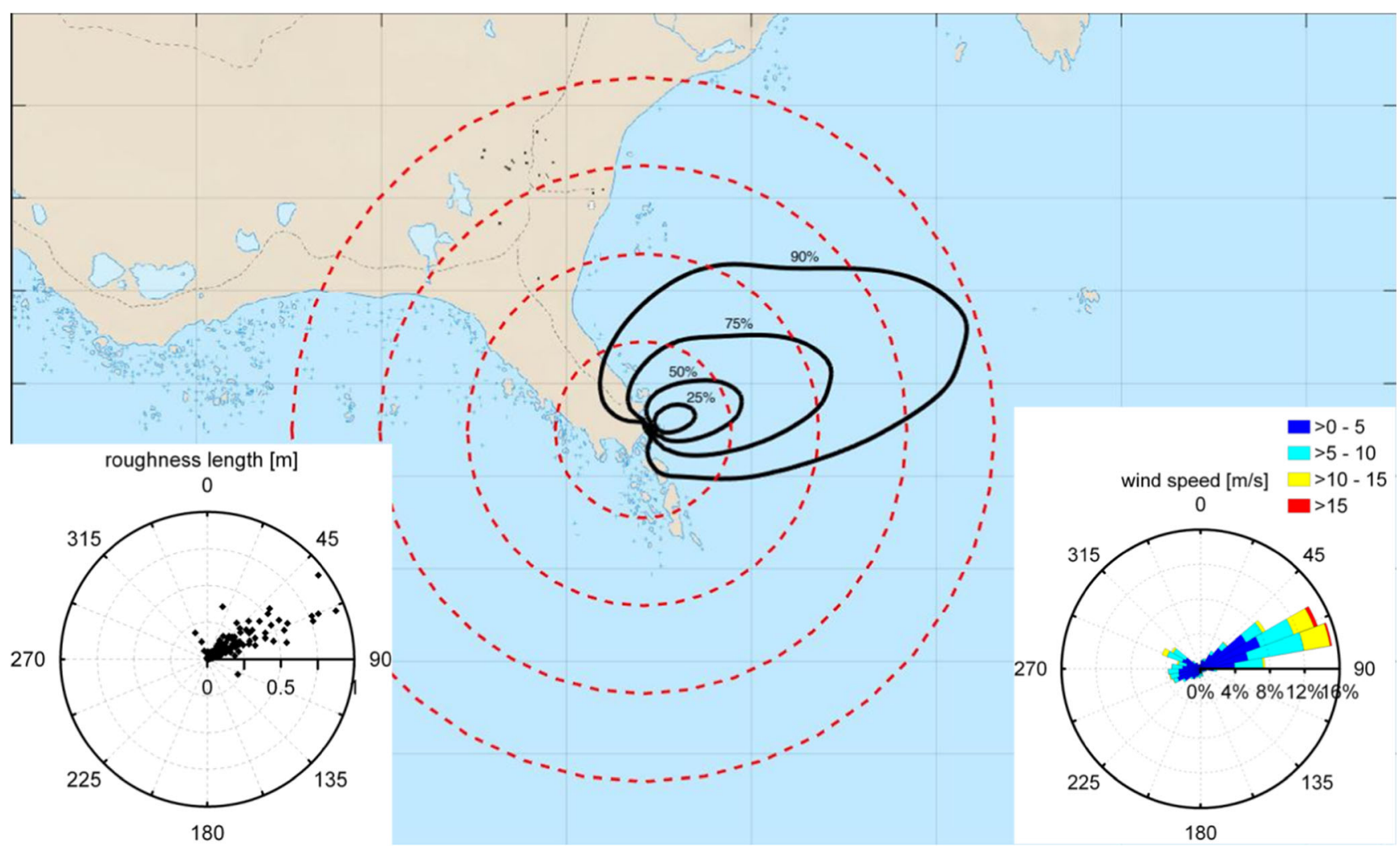

Fig. 2 Source area of turbulent fluxes (with probability $p=25,50,75$ and $90 \%$ ) calculated for unstable conditions with use of Schmid method (main figure). Additional figures show relations between wind direction and roughness length (left) and wind speed (right). Map source: TopoSvalbard 
to which the mast was attached. The values of individual radiation fluxes were recorded using a LOGBOX SD data logger at a frequency of $1 \mathrm{~min}$. These radiation fluxes then served to determine the amount of energy, both incoming and lost at the surface, in hourly intervals. The albedo, shortwave and longwave radiation balance and the solar radiation balance were calculated. At the same time, basic meteorological elements - atmospheric pressure, wind speed and direction, air temperature and relative humidity and precipitation-were automatically recorded every $10 \mathrm{~min}$ at the site using a Vantage Pro+ station.

\section{Methodology}

The eddy covariance is the most direct way to derive the turbulent fluxes of sensible and latent heat, $\left(Q_{H}\right.$ and $Q_{E}$, respectively, in $\mathrm{Wm}^{-2}$ ), using a high frequency data of temperature, $T\left({ }^{\circ} \mathrm{K}\right)$, specific humidity, $q(\mathrm{~kg} / \mathrm{kg})$ and vertical wind speed $w\left(\mathrm{~m} \mathrm{~s}^{-1}\right)$ (Swinbank 1951).

$Q_{H}=\rho c_{p} \overline{w^{\prime} T^{\prime}}$,

$Q_{E}=\rho l \overline{w^{\prime} q^{\prime}}$,

where $\rho$ is air density $\left(\mathrm{kg} \mathrm{m}^{-3}\right), c_{p}\left(\mathrm{~J} \mathrm{~kg}^{-1} \mathrm{~K}^{-1}\right)$ is the specific heat capacity of dry air at constant pressure, $l\left(\mathrm{~J} \mathrm{~kg}^{-1}\right)$ is the latent heat of evaporation and the prims denote fluctuations and overbars the average operator. In spite of the simplicity of the above equations, the flux calculations needed corrections as well as pre- and post-processing to achieve a high quality data set. The methodology for obtaining high-quality data was worked out by the EC community in recent years (Lee et al. 2004; Aubinet et al. 2012).

In the present study, the turbulent fluxes were derived through the following steps, which are typically used in flux calculations. First, the spikes were removed from the raw data following Vickers and Mahrt (1997). Any values which exceeded 4.5 times standard deviations in a window of 10 values were labelled as spikes and replaced by the window mean. Outranged values were eliminated based on physical thresholds. The cross-wind correction was implemented in the sonic anemometer. Lag between the sonic measurements and the hygrometer was determined at the point of maximum correlation between absolute humidity and vertical velocity in the window $\pm 2 \mathrm{~s}$. Fluxes were calculated in a rotated, natural wind coordinate system with double rotation (Kaimal and Finnigan 1994). We used classical block averaging with 1-h intervals because only this averaging method fulfils the theoretical assumption of turbulent flux calculations (Reynolds averaging), and it is commonly used by other groups. Corrections were applied to $Q_{H}$ to account for the impact of humidity on sonic temperature (Schotanus et al. 1983) and to $Q_{E}$ for oxygen absorption across the krypton hygrometer's bandwidth (van van Dijk et al. 2003). Additional Webb-Pearman-Leuning (WPL) correction (Webb et al. 1980) allowed for inclusion of a mass imbalance effect on vertical velocity. Finally, a simple analytical formula from Horst and Lenschow (2009) was applied to the base for correction of spectral losses.

The weakness of the open-path EC method is its sensitivity to heavy weather conditions. The humidity measurements by the krypton hygrometer failed in the case of precipitation, dew and frost deposition. Similarly, sea salt deposition on the transmitters could reduce their signal and direct solar radiation might amplify the signal when it illuminates the receiver. The sonic anemometer is less sensitive to weather conditions, but precipitation, dew and frost also affect its measurements. As a consequence, the number of acceptable data could be considerably reduced. These disadvantages especially affect the number of available data obtainable in the extreme environmental conditions observed in the Arctic. Moreover, to achieve the study goal, the data were limited to the wind from the eastern sector (Fig. 2). The theoretical basis of the method imposes additional restrictions on the number of available data. Reliable flux estimation with the EC technique is only possible when the analysed data meet a stationarity postulate. The technique can be verified by different tests which allow for obtaining high-quality data. Three stationarity tests were used in this work: the first was proposed by Foken and Wichura (1996), the second by Mahrt (1998) and the third by Dutaur et al. (1999) and Nemitz et al. (2002). More details about these tests can be found in Fortuniak et al. (2013). We decided to use more than one test, because of the individual tests' limitations. For example, the most common Foken and Wichura test can give misleading information in situations when turbulent flux is close to zero. Furthermore, in the final analysis, two data sets were used: data approved by at least one of the tests (hereafter denoted as $1 \mathrm{~T}$ data) and data approved by all three tests (hereafter denoted as $3 \mathrm{~T}$ data). The motivation for this approach was to get the most comprehensive view of the turbulent energy exchange in Hornsundfjord. The conjunction of three tests gave high-quality data, but significantly reduced the number of available data, and this could lead to an unrealistic monthly statistic. Disjunction left more data, but of a lower quality. Data selection before stationary tests lead to about $50 \%$ of the excluded data. For the $1 \mathrm{~T}$ data (data approved by at least one test), the stationarity tests reduced the number of available data by another $16 \%$. In consequence, after all data selection, only $34 \%$ of the original data was usable for analysis. The number of available data approved by the $3 \mathrm{~T}$ data set were further reduced to about $12 \%$ of the whole. In certain months, the percentage of good data could be even lower (Fig. 3). The monthly statistics based on such limited data could be significantly affected by selected days with good data. On the other hand, in some cases, the results suggested extremely intensive surface energy 
Fig. 3 The percentage of the data approved by all three stationarity tests and by at least one of the tests

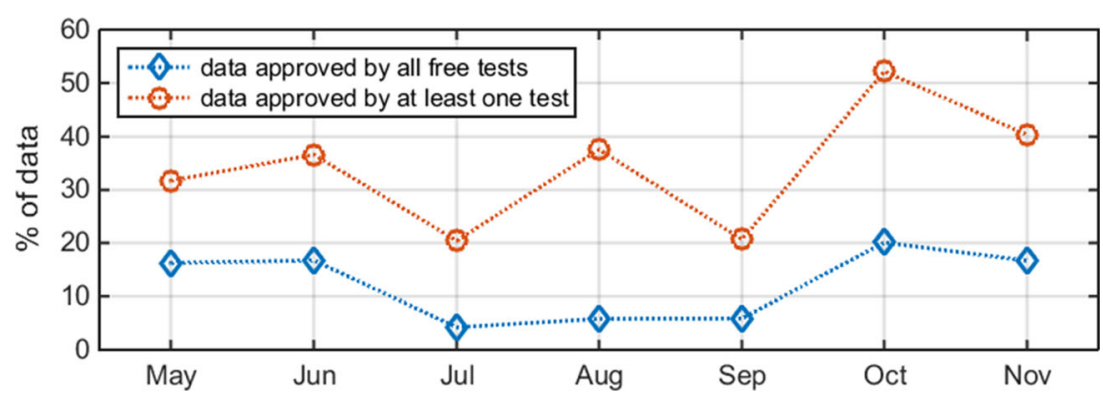

exchange. Ultimately, the estimation of extremes had to be based on high-quality, trustworthy data. For these reasons, we decided to present the results for both data sets.

\section{Results and discussion}

The weather conditions that prevailed at the Hornsund station, situated $700 \mathrm{~m}$ north of the thermal balance measurement site, from May to November 2014 are presented in Fig. 4 and compared in Table 1 with the values recorded for 1978 2012. The whole period from May to November was warmer than during the multi-year period. Of all months considered, October is of particular interest here, as it was $2.9^{\circ} \mathrm{C}$ warmer than the multi-year values determined for that month. In the analysed period, there was also a greater amount of sunshine compared with the long-term value (Table 1), especially in August 2014 when the monthly value of effective sunshine duration (212.7 h) (Fig. 4) was the highest ever recorded at Hornsund. The mean cloud amount (on a scale of 0-8) in all the months was $0.9-2.2$ greater. From May to November 2014, the atmospheric pressure was also higher, which effectively slowed the wind (except in September) as compared with the multi-year values. The relative humidity and precipitation values over the entire investigated period were close to standard. In the case of precipitation, its monthly sums were notably lower than during the multi-year period in August (by $37.0 \mathrm{~mm}$ ) and higher in September (by $23.7 \mathrm{~mm}$ ).

The turbulent fluxes are determined by the temperature and humidity gradients (related to the radiation balance), by the surface properties and by the mechanical turbulence from wind shear. In the analysed period the radiation balance, $Q^{*}$, was in general positive to the mid-September when the longwave losses overcame shortwave incomings (Fig. 5). The average value of $Q^{*}$ for the entire period was $50 \mathrm{Wm}^{-2}$. In June and July, it was 158 and $151 \mathrm{Wm}^{-2}$, respectively. May and August were characterized by $Q^{*}$ being slightly more than half of these values $\left(90\right.$ and $80 \mathrm{Wm}^{-2}$ ). In September $Q^{*}$ dropped to close to zero $\left(5 \mathrm{Wm}^{-2}\right)$ and became negative in the last two months: $-30 \mathrm{Wm}^{-2}$ in October and $-41 \mathrm{Wm}^{-2}$ in November. The maxima of $Q^{*}=496 \mathrm{Wm}^{-2}$ were recorded in June and July, and the minima in September $\left(-86 \mathrm{Wm}^{-2}\right)$ and November $\left(-89 \mathrm{Wm}^{-2}\right)$. The highest solar radiation, $K_{d}$, was recorded in June when it reached above $630 \mathrm{Wm}^{-2}$ in a sunny noontime, with mean value $237 \mathrm{Wm}^{-2}$. Similar values were recorded in May and July (mean $225 \mathrm{Wm}^{-2}$ ). Due to the shortening of the days' length and the reduction of the Sun's altitude above the horizon, $K_{d}$ decreased from the beginning of August to the end of October when the polar nights began (31st of October). Downward longwave radiation, $L_{d}$, remained on a similar level from June to November in averages of $300-310 \mathrm{Wm}^{-2}$, with a slightly higher value $\left(317 \mathrm{Wm}^{-2}\right)$ in October. In May, it was significantly lower, averaging about $250 \mathrm{Wm}^{-2}$. The highest absolute $L_{d}=373 \mathrm{Wm}^{-2}$ was recorded in October and the lowest $L_{d}=203 \mathrm{Wm}^{-2}$ in May. Similarly to $L_{d}$, the upward longwave radiation, $L_{u}$, reached its lowest values in May, with average $318 \mathrm{Wm}^{-2}$ and the minimum recorded $L_{u}=285 \mathrm{Wm}^{-2}$. The highest mean values of $L_{u}$ were recorded from June to August (on the level 354-360 $\mathrm{Wm}^{-2}$ ) and in October $\left(349 \mathrm{Wm}^{-2}\right.$ ). In September and November, mean $L_{u}$ was slightly lower (333 and $336 \mathrm{Wm}^{-2}$, respectively).

The surface temperature of sea water in the Arctic fjords is not a simple function of radiation balance, but is affected by the water flow in the fjords' canals, the mixing of sea water with fresh water from glacial melt, and the presence of glacial ice. In the analysed period, the sea's surface water temperature was in general positive from the second half of May to the second 10 days of October, but some occurrences of negative values happened during and just after the intensive glacial calving. This resulted in the presence of glacial ice in the fjord and in such situations the water temperature dropped from a few degrees above zero to $-0.2{ }^{\circ} \mathrm{C}$ when brash ice dominated in the fjord's water and below $-1{ }^{\circ} \mathrm{C}$ when a large density of ice growlers occurred. Since October 8, the negative water temperature favoured ice formation in coastal areas. The surface albedo (Fig. 5) reflects the changes in ice conditions in the study period. The low values represent the ice-free conditions observed mainly in June and July. High values of albedo are related to increased ice cover.

The thermally generated turbulence (buoyancy convection) is steered by the air-water temperature contrasts determined by the above processes. One stability parameter, defined as $\zeta=z$ $' / L$, can be the non-dimensional measure of buoyancy forces, where the $z^{\prime}$ is measurement height corrected by displacement height and $L$ is the Obukhov length. Negative values of $\zeta$ 
Fig. 4 Course of meteorological elements in Hornsund in the period from May 1 to November 30, 2014. Ti mean, $T$ max maximum air temperature, $T$ min minimum air temperature, $S S$ sunshine duration, $D D$ duration of the day, $C$ cloudiness $f$ relative air humidity, $V$ wind velocity at $10 \mathrm{~m}$ a.s.l., $P a$ air pressure at $0 \mathrm{~m}$ a.s.l., $P$ precipitation
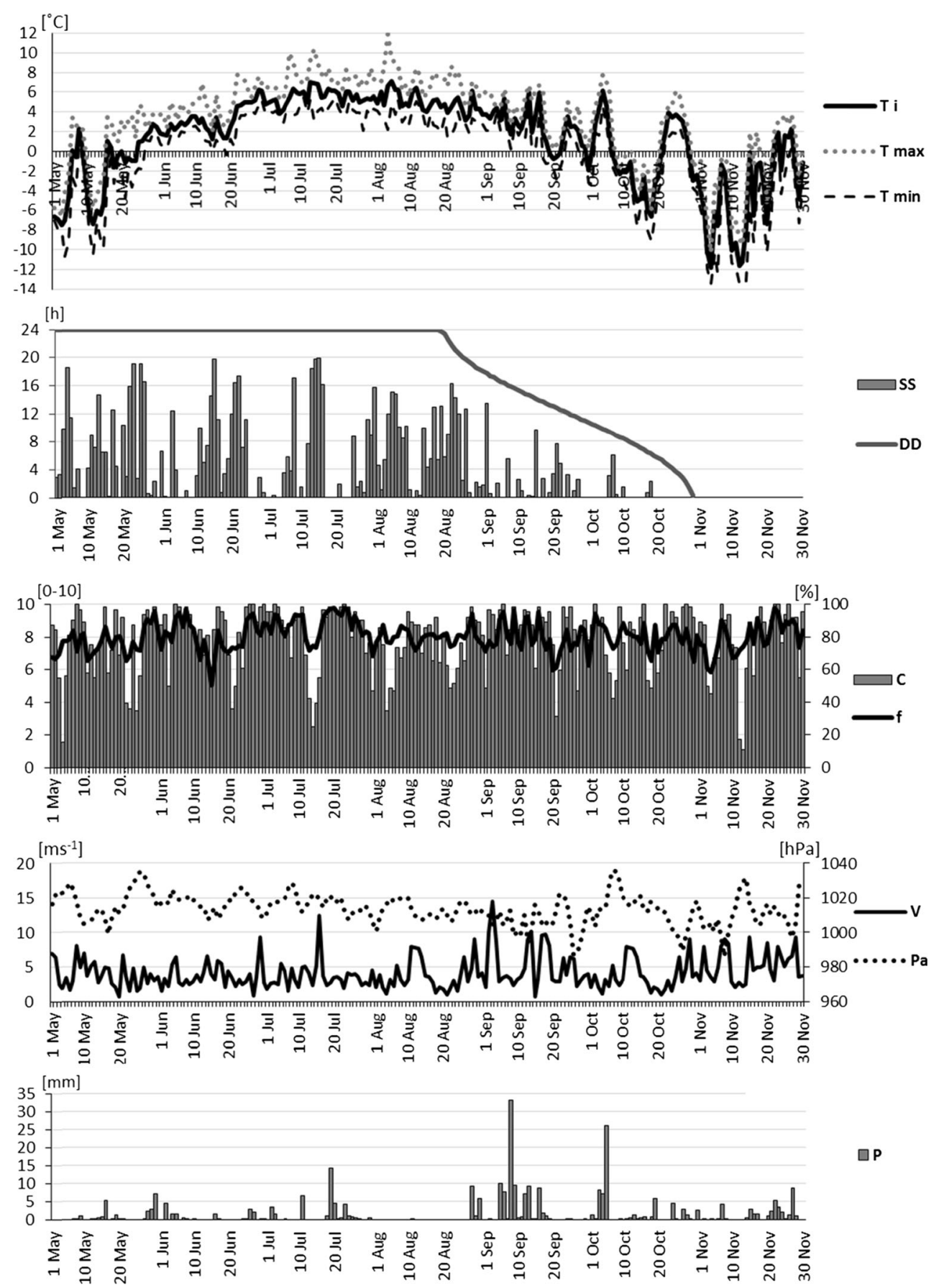

denote locally unstable situations; positive are stable ones. The data used in the analysis represented unstable situations at the beginning and end of the analysed period and close to neutral in the middle (Fig. 6). In May and June especially, water being relatively warmer than air created a noticeably unstable stratification, which forced intensive convection mixing. From July to September, the analysed cases represented close to neutral stratification, with weakly stable situations in August. In the last 2 months of observation, the stratification again turned to weakly unstable. For the entire analysed period, $81 \%$ of data approved by all three tests represented unstable situations $(\zeta<0)$. The other $19 \%$ was recorded for $\zeta>0$, but the majority (16\%) were for very weakly stable situations $(0<\zeta<0.1)$. In general, more than half $(56 \%)$ of the 3T data sets were recorded in close to neutral situations $(-0.1<\zeta<0.1)$. The diurnal course of $\zeta$ is poorly pronounced, which is a consequence of both the specific radiation course in polar regions and high thermal inertia of the water's surface.

Another factor governing the surface mass and energy exchange is mechanical turbulence intensity. The friction 
Table 1 Monthly mean and sum anomalies of main meteorological variables in Hornsund from May to November 2014 (b) in relation to reference period 1978-2012 (a)

\begin{tabular}{ccccccccc}
\hline Variable & Period & May & Jun & Jul & Aug & Sep & Oct & Nov \\
\hline $\mathrm{Ti}\left({ }^{\circ} \mathrm{C}\right)$ & $\mathrm{a}$ & -2.7 & 1.9 & 4.4 & 4.1 & 1.5 & -3.2 & -6.3 \\
& $\mathrm{~b}$ & 0.8 & 1.4 & 1.2 & 0.9 & 0.9 & 2.9 & 1.9 \\
$\mathrm{SS}(\mathrm{h})$ & $\mathrm{a}$ & 205.4 & 171.0 & 155.4 & 124.9 & 73.7 & 22.8 & - \\
& $\mathrm{b}$ & 6.6 & -6.1 & 8.5 & 87.8 & -13.3 & -9.1 & - \\
$\mathrm{SS}(\%)$ & $\mathrm{a}$ & 27.6 & 23.8 & 20.9 & 17.9 & 17.4 & 11.6 & - \\
$\mathrm{C}(0-8)$ & $\mathrm{b}$ & 0.9 & -0.9 & 1.1 & 12.6 & -3.1 & -4.6 & - \\
& $\mathrm{a}$ & 6.0 & 6.4 & 6.5 & 6.5 & 6.5 & 5.9 & 5.6 \\
$\mathrm{~Pa}(\mathrm{hPa})$ & $\mathrm{b}$ & 1.4 & 1.9 & 1.8 & 0.9 & 1.8 & 2.2 & 2.2 \\
& $\mathrm{a}$ & 1016.3 & 1013.4 & 1012.2 & 1011.9 & 1008.6 & 1007.5 & 1005.6 \\
$\mathrm{~V}\left(\mathrm{~m} \mathrm{~s}{ }^{-1}\right)$ & $\mathrm{b}$ & 1.8 & 3.8 & 4.6 & 1.0 & -2.2 & 6.2 & 4.5 \\
& $\mathrm{a}$ & 4.9 & 3.9 & 4.0 & 4.1 & 4.5 & 5.3 & 6.1 \\
$\mathrm{f}(\%)$ & $\mathrm{b}$ & -1.0 & -0.3 & -0.3 & -0.4 & 0.7 & -1.6 & -0.8 \\
& $\mathrm{a}$ & 79 & 83 & 86 & 86 & 82 & 77 & 76 \\
$\mathrm{P}(\mathrm{mm})$ & $\mathrm{b}$ & -2 & -3 & 1 & -5 & -3 & 4 & 4 \\
& $\mathrm{a}$ & 20.1 & 27.7 & 41.2 & 53.6 & 68.3 & 47.3 & 38.1 \\
& $\mathrm{~b}$ & 2.9 & -11.0 & -1.8 & -37.0 & 23.7 & 18.1 & -0.3 \\
\hline
\end{tabular}

$T i$ air temperature, $S S$ sunshine duration, $C$ cloudiness, $P a$ air pressure at $0 \mathrm{~m}$ a.s.l., $V$ wind velocity at $10 \mathrm{~m}$ a.s.l., $f$ relative air humidity, $P$ precipitation, $a$ period 1978-2012 (Styszyńska 2013), $b$ deviation of main meteorological variables in 2014 from reference period a velocity, $u_{*}$, in the selected data (Fig. 7) proves that all measurements were conducted under well-developed turbulence conditions. Most of the $u *$ values ranges from 0.2 to $0.4 \mathrm{~ms}^{-1}$. Neither seasonal nor diurnal regularity can be observed. In the 3T data set the increased values were observed in July, which was a consequence of the fact that the good data approved by three tests for this month came from a period of windy days, with wind speed around $10 \mathrm{~ms}^{-1}$. Whereas in other months, the data used in the analysis were related to lower wind speed, mainly around $5 \mathrm{~ms}^{-1}$. The $1 \mathrm{~T}$ data set, which uses more data than the $3 \mathrm{~T}$, showed that the increased $u_{*}$ in July in the $3 \mathrm{~T}$ is not representative of the whole month.

Inspection of all of the $1 \mathrm{~h}$ data for the analysed period (Fig. 8) shows a moderate energy exchange by a sensible heat flux, $Q_{H}$, with the mean of about $17.5 \mathrm{Wm}^{-2}$ (Table 2) when calculated for the $3 \mathrm{~T}$ data set and $7.5 \mathrm{Wm}^{-2}$ for the 1T. The 25 and $75 \%$ percentiles ranged from about 5 to $40 \mathrm{Wm}^{-2}$ for $3 \mathrm{~T}$ and from -11 to $28 \mathrm{Wm}^{-2}$ for $1 \mathrm{~T}$. The $Q_{H}$ flux undergoes a clear seasonal regularity with downward heat transport (negative fluxes) from July to September of the analysed period, close to zero in October, and upward in other months. The absolute values of the monthly means are lower for $1 \mathrm{~T}$ than for 3T, which can be an effect of excluding cases of close to zero fluxes by one of the stationarity tests from the analysis. On average, the most intensive downward heat transport occurred in the late summer, when calving glaciers cooled sea water in the fjord and the air remained relatively warm. This downward transport was on average at a level of -(1530) $\mathrm{Wm}^{-2}$, and different data selections point to different months as being most favourable for turbulent air cooling (August for 3T with $Q_{H}=-27 \mathrm{Wm}^{-2}$ and September for $1 \mathrm{~T}$ with $Q_{H}=-19 \mathrm{Wm}^{-2}$ ). The most intensive air warming happened in November when $Q_{H}$ reached an average $50 \mathrm{Wm}^{-2}$ for $3 \mathrm{~T}$ and $34 \mathrm{Wm}^{-2}$ for $1 \mathrm{~T}$. Slightly lower, but on average also clearly positive fluxes were recorded in May. The highest $Q_{H}$ recorded in the analysed period, approved by all three tests, was $150 \mathrm{Wm}^{-2}$ in November and below $-165 \mathrm{Wm}^{-2}$ in the October. The large variability of air temperature in last 2 months of the analysed period was the reason for the high variability of $Q_{H}$. In both cases, the differences between the maximum and minimum $Q_{H}$ reached up to about $250 \mathrm{Wm}^{-2}$. The box-whiskers plot for all $24 \mathrm{~h}$ in the analysed period
Fig. 5 Course of daily means of albedo, radiation balance and its components in the period from May 1 to November 30,2014, in Hornsund. $Q^{*}$ radiation balance, $K d$ incoming solar radiation, $K_{u}$ reflected solar radiation, $L_{d}$ incoming longwave radiation, $L_{u}$ outgoing longwave radiation
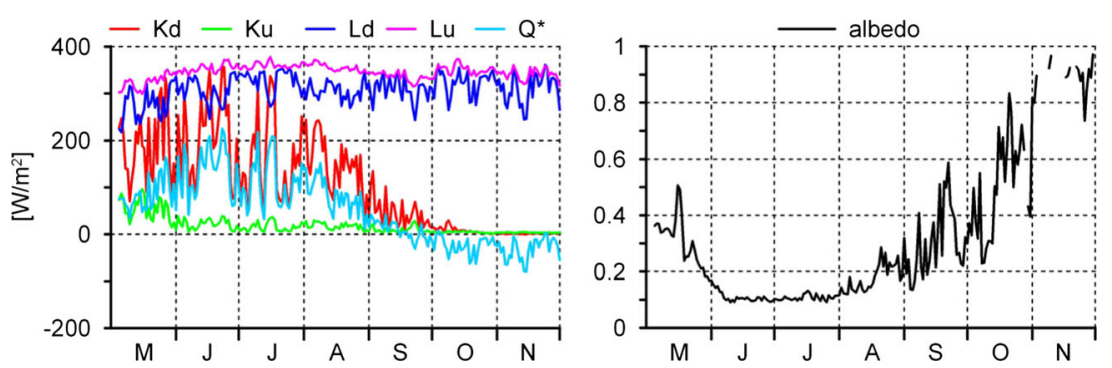
Fig. 6 Box-whiskers plots for the stability parameter, $\zeta=z^{\prime} / L$, for months (left) and hours (right) in Hornsund in the period from May 1 to November 30, 2014. The upper plots based on the data approved by all three stationarity tests (3T), the lower plots based on the data approved by only one of the stationarity tests (1T). On each box, the central mark is the median, the edges of the box are the 25th and 75th percentiles, the whiskers extend to the most extreme data points not considered outliers and outliers are plotted individually. Points are drawn as outliers when they differ more than 2.7 standard deviations from the mean
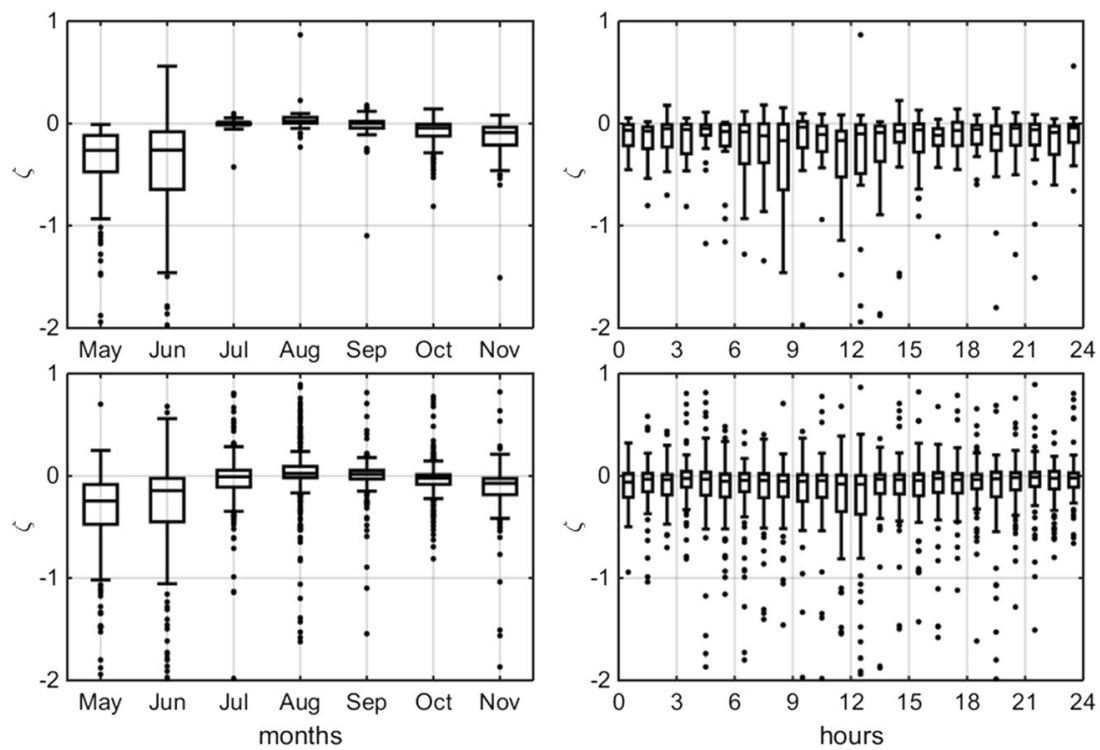

shows that the $Q_{H}$ did not undergo a diurnal clear cycle. This is a consequence of the lack of diurnal variation in either mechanical (expressed by $u_{*}$ ) or thermal (expressed by $\zeta$ ) turbulence intensity.

The analysis of the latent heat flux, $Q_{E}$, suggests more intensive energy exchanges due to evaporation than direct heating (Fig. 9). The average $Q_{E}$ for all of May-November was quite similar for both the 3T and 1T data sets: 95 and $90 \mathrm{Wm}^{-2}$ respectively. There were no differences between the two data sets in the upper quartile equal to $109 \mathrm{Wm}^{-2}$. The lower quartile for $3 \mathrm{~T}$ was $37 \mathrm{Wm}^{-2}$ and for $1 \mathrm{~T}$ it was slightly lower, at $30 \mathrm{Wm}^{-2}$. The main differences between the results for the $1 \mathrm{~T}$ and $3 \mathrm{~T}$ datasets were the only positive values recorded in 3T. This means no net downward water vapour transport from air to sea. As only positive humidity fluxes seems to be reasonable from the point of view of physical processes over an open water reservoir, the negative $Q_{E}$ approved by only one test could be a spurious consequence of non-stationarity, missed by one of the tests. The monthly means are on a level of about $70 \mathrm{Wm}^{-2}$ from May to September for both data sets, except in July. For this month, the very limited number of good data in the $3 \mathrm{~T}$ data set resulted in an extraordinary mean value of $133 \mathrm{Wm}^{-2}$ (Table 2). The selected measurements were made in windy conditions exaggerating turbulent transport. The $1 \mathrm{~T}$ mean for this month is much lower $\left(83 \mathrm{Wm}^{-2}\right)$. The beginning of the winter brought an increase of monthly averages to about $100 \mathrm{Wm}^{-2}$ in October and $139 \mathrm{Wm}^{-2}$ in November (similarly for both 1T and 3T). It is worth mentioning that due to the asymmetry of $Q_{E}$ distribution, the median values were clearly lower than the means. For the whole May-November period, these were $57 \mathrm{Wm}^{-2}$ for $1 \mathrm{~T}$ and $59 \mathrm{Wm}^{-2}$ for 3T. It then ranged from about $40 \mathrm{Wm}^{-2}$ in September to $85 \mathrm{Wm}^{-2}$ in November (similarly for both $1 \mathrm{~T}$ and $3 \mathrm{~T}$ ). The single exception was a median
Fig. 7 The same as at Fig. 6 but for a friction velocity, $u *$
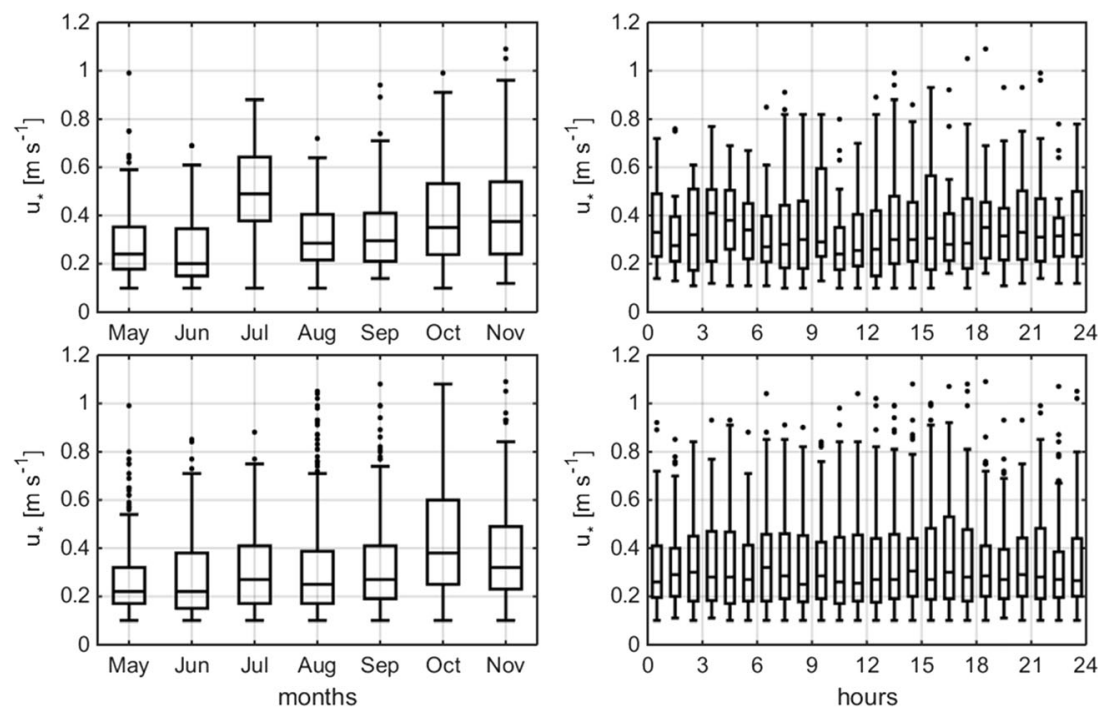
Fig. 8 The same as at Fig. 6 but for sensible heat flux, $Q_{H}$

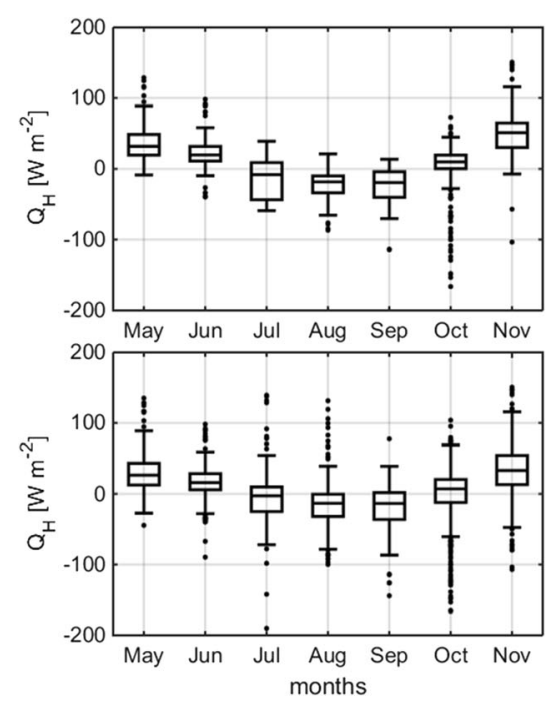

for June for the $3 \mathrm{~T}$ data set of $142 \mathrm{Wm}^{-2}$. The most striking feature of $Q_{E}$ was the extremely large flux. $Q_{E}$ higher than $200 \mathrm{Wm}^{-2}$ was recorded in all months, and in a few cases, the maxima approved by all three tests exceeded $500 \mathrm{Wm}^{-2}$. All cases $(n=50)$ of extremely intensive latent heat flux $\left(Q_{E}>250 \mathrm{Wm}^{-2}\right)$ were observed in a close to neutral stratification of $-0.1<\zeta<0.05$, mainly in weakly unstable situations. The unstable situations $(\zeta<-0.5)$ resulted in a moderate $Q_{E}$, less than $100 \mathrm{Wm}^{-2}$.

The radiation balance and turbulent fluxes determine the amount of heat released from the sea water to the atmosphere. It can be evaluated as a rest of the energy balance: $Q_{\text {rest }}=Q^{*}-Q_{H}-Q_{E}$ (Fig. 10). Positive values of $Q_{\text {rest }}$ indicate a general heating of the surface water by the sum of other fluxes, negative values, general cooling of the water and heating of the atmosphere by energy expelled by the water. The monthly means of $Q_{\text {rest }}$ in the $3 \mathrm{~T}$ data set were positive in June and July (109 $\mathrm{Wm}^{-2}$ and $84 \mathrm{Wm}^{-2}$, respectively), close to zero in May and August ( 5 and $-3 \mathrm{Wm}^{-2}$ ) and negative in the last 3 months, with the strongest water cooling $\left(268 \mathrm{Wm}^{-2}\right)$ in November. The mean value for MayNovember was $60 \mathrm{Wm}^{-2}$. The similar mean value $\left(55 \mathrm{Wm}^{-2}\right)$ can be derived from analysis of the $1 \mathrm{~T}$ dataset, but in particular the month differences in monthly means between the two datasets can reach $65 \mathrm{Wm}^{-2}$ in September and about $35 \mathrm{Wm}^{-2}$ in June, August and November, while a level
Table 2 Monthly statistics of sensible $\left(Q_{H}\right.$ in $\left.\mathrm{Wm}^{-2}\right) \mathrm{m}$ and latent $\left(Q_{E}\right.$ in $\left.\mathrm{Wm}^{-2}\right)$ heat fluxes in Hornsund in the period from May 1 to November 30, 2014 (mean, standard deviation and percentiles) calculated on the base on data which passed all three stationarity tests

\begin{tabular}{|c|c|c|c|c|c|c|c|c|c|}
\hline & & May & Jun & Jul & Aug & Sep & Oct & Nov & May-Nov \\
\hline Mean & $Q_{H}$ & 38.3 & 23.0 & -13.8 & -26.7 & -24.4 & -3.0 & 50.5 & 17.5 \\
\hline St. dev. & & 26.1 & 24.0 & 29.3 & 24.4 & 30.5 & 44.0 & 36.3 & 42.1 \\
\hline $1 \%$ & & 0.6 & -39.4 & -59.1 & -86.8 & -114.4 & -152.8 & -69.2 & -114.4 \\
\hline $10 \%$ & & 11.6 & 5.5 & -48.2 & -67.7 & -59.3 & -68.9 & 15.4 & -33.9 \\
\hline $25 \%$ & & 19.7 & 11.2 & -43.5 & -33.7 & -40.1 & 0.5 & 30.4 & 4.7 \\
\hline $50 \%$ (median) & & 32.0 & 19.9 & -8.1 & -18.2 & -19.3 & 10.1 & 51.4 & 18.8 \\
\hline $75 \%$ & & 48.9 & 31.9 & 9.1 & -9.8 & -3.9 & 19.7 & 65.0 & 39.1 \\
\hline $90 \%$ & & 75.5 & 52.8 & 22.2 & -6.9 & 10.9 & 31.5 & 92.3 & 61.0 \\
\hline $99 \%$ & & 125.3 & 93.1 & 39.3 & 21.4 & 13.7 & 59.9 & 148.2 & 126.8 \\
\hline Mean & $Q_{E}$ & 71.8 & 71.3 & 133.3 & 68.6 & 77.1 & 97.2 & 139.9 & 94.9 \\
\hline St. dev. & & 73.8 & 63.5 & 67.5 & 43.9 & 115.5 & 92.7 & 133.3 & 96.0 \\
\hline $1 \%$ & & 13.6 & 10.6 & 16.2 & 8.9 & 8.3 & 8.3 & 11.5 & 10.4 \\
\hline $10 \%$ & & 26.1 & 25.4 & 39.9 & 18.0 & 20.2 & 25.5 & 33.9 & 26.3 \\
\hline $25 \%$ & & 36.0 & 32.7 & 94.8 & 37.6 & 27.4 & 36.6 & 45.6 & 37.1 \\
\hline $50 \%$ (median) & & 53.3 & 46.5 & 141.7 & 60.0 & 39.9 & 58.5 & 83.1 & 59.2 \\
\hline $75 \%$ & & 82.8 & 85.6 & 174.8 & 95.6 & 61.8 & 135.9 & 178.3 & 109.2 \\
\hline $90 \%$ & & 112.5 & 138.0 & 234.3 & 105.5 & 193.0 & 204.5 & 392.0 & 210.5 \\
\hline $99 \%$ & & 465.4 & 321.3 & 269.1 & 213.5 & 547.0 & 414.1 & 505.8 & 466.6 \\
\hline
\end{tabular}


Fig. 9 The same as at Fig. 6 but for latent heat flux, $Q_{E}$
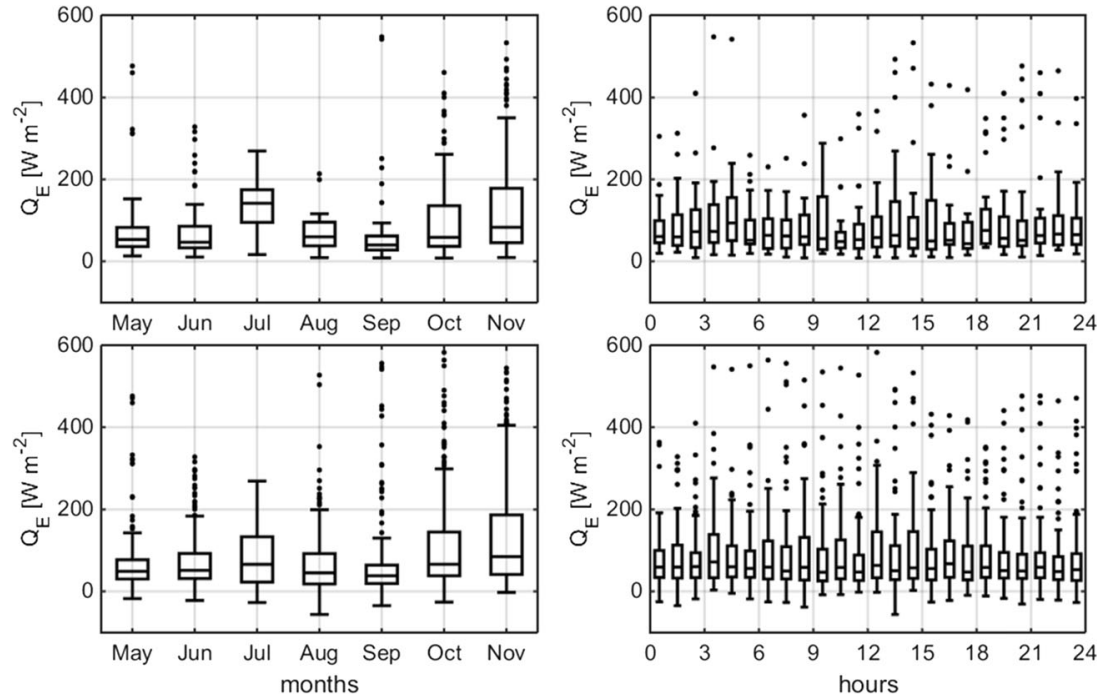

of just a few $\mathrm{Wm}^{-2}$ holds true in other months. Still, the differences are in a range of variability - the standard deviations of $Q_{\text {rest }}$ are above $100 \mathrm{Wm}^{-2}$ in all months for both data sets and reach almost $180 \mathrm{Wm}^{-2}$ for the entire period.

\section{Conclusions}

The results show the complexity of the surface energy exchange between sea water and atmosphere in Arctic fjords. This turbulent exchange is dominated by latent heat flux, which on average is significantly higher than a sensible heat flux. The dominant latent heat flux is in general upward, which indicates a sea surface cooling by evaporation. On average, $Q_{E}$ remained on a constant level of around $70 \mathrm{Wm}^{-2}$ in the summer, increasing at the beginning of winter. The sensible heat flux was significantly lower and took negative values from July to October, which means downward turbulent transport of heat to the surface and might be related to the presence of glacial ice in the fjord, with melting ice consuming heat from the surface air layer. One remarkable feature of the turbulent energy exchange in this Arctic fjord was the sporadic appearance of very high values of latent heat, with the maxima exceeding $500 \mathrm{Wm}^{-2}$, which happened close to neutral stratification. This indicates that under favourable conditions, the sea-air energy exchange could be very intensive.

The results also show the difficulties in estimating turbulent fluxes in the Arctic with the aid of the eddy covariance method. The extreme weather conditions result in a large number of data being excluded from analysis, either due to sensor failures or to the non-fulfilling theoretical assumptions of the method. Moreover, even if standard steps in flux calculations have been well worked out by the EC community, data quality verification is more subjective. Each stationarity test approves a slightly different set of data, while the choice of tests used and their combination remain a subjective decision. With large amounts of excluded data, this can significantly affect the results, especially when the approved data are used in gap-
Fig. 10 The same as at Fig. 6. but for the rest from the energy balance: $Q^{*}-Q_{H}-Q_{E}$
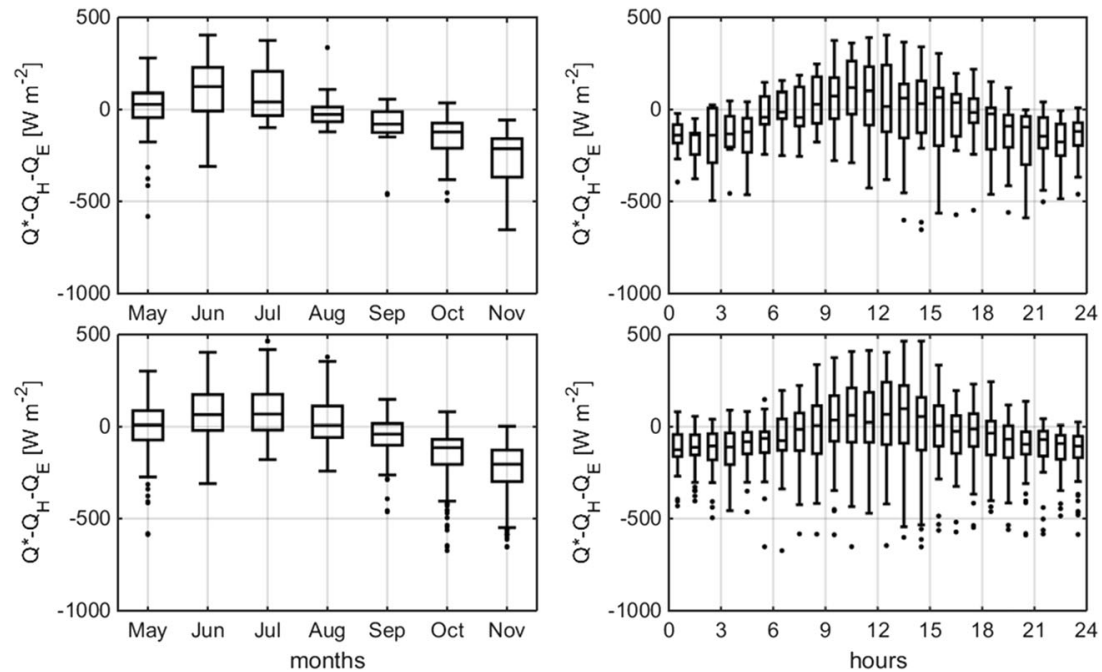
filling procedures. The monthly totals of energy based on such procedures can be tilted toward making a case for approved data, but which are not necessary representative of the prevailing weather conditions.

Acknowledgments The research work was supported by the PolishNorwegian Fund as part of the 'Arctic Climate System Study of Ocean, Sea Ice and Glaciers' Interactions in the Svalbard Area' project (AWAKE 2 ) and by a grant entitled 'Contemporary and historical changes in the Svalbard climate and topoclimates', funded by the National Science Centre with decision No. DEC-2011/03/B/ST10/05007.

Open Access This article is distributed under the terms of the Creative Commons Attribution 4.0 International License (http:// creativecommons.org/licenses/by/4.0/), which permits unrestricted use, distribution, and reproduction in any medium, provided you give appropriate credit to the original author(s) and the source, provide a link to the Creative Commons license, and indicate if changes were made.

\section{References}

Argentini S, Viola AP, Mastrantonio G, Maurizi A, Georgiadis T, Nardino M (2003) Characteristics of the boundary layer at Ny-Ålesund in the Arctic during the ARTIST field experiment. Ann Geophys-Italy 46(2):185-195

Aubinet M, Vesala T, Papale D (eds) (2012) Eddy covariance: a practical guide to measurement and data analysis. Springer, Berlin, $460 \mathrm{pp}$

Bednorz E (2011) Occurrence of winter air temperature extremes in Central Spitsbergen. Theor Appl Climatol 106(3-4):547-556

Dutaur L, Cieslik S, Carrara A, Lopez A (1999) The detection of nonstationarity in the determination of deposition fluxes. Proceedings of EUROTRAC Symposium '98, vol. 2. WIT Press, Southampton, pp 171-176

Foken T, Wichura B (1996) Tools for quality assessment of surface-based flux measurements. Agric For Meteorol 78:83-105

Fortuniak K, Pawlak W, Siedlecki M (2013) Integral turbulence statistics over a central European city centre. Bound-Layer Meteorol 146: 257-276

Grachev AA, Fairall CW, Persson POG, Andreas EL, Guest PS (2005) Stable boundary-layer scaling regimes: the SHEBA data. BoundLayer Meteorol 116:201-235

Grachev AA, Andreas EL, Fairall CW, Guest PS, Persson POG (2007) SHEBA flux-profile relationships in the stable atmospheric boundary layer. Bound-Layer Meteorol 124:315-333

Grachev AA, Andreas EL, Fairall CW, Guest PS, Persson POG (2008) Turbulent measurements in the stable atmospheric boundary layer during SHEBA: ten years after. Acta Geophys 56:142-166

Häkkinen S, Cavalieri DJ (1989) A study of oceanic surface heat fluxes in the Greenland, Norwegian, and Barents Sea. J Geophys Res 94: 6145-6157

Harding R, Lloyd C (1998) Fluxes of water and energy from three high latitude tundra sites in Svalbard. Nord Hydrol 29:267-284

Horst TW, Lenschow DH (2009) Attenuation of scalar fluxes measured with spatially-displaced sensors. Bound-Layer Meteorol 130:275-300

Kaimal JC, Finnigan JJ (1994) Atmospheric boundary flows. Their structure and measurement. Oxford Univ Press, 289 pp

Kilpeläinen T, Sjöblom A (2010) Momentum and sensible heat exchange in an ice-free Arctic fjord. Bound-Layer Meteorol 134:109-130

Kral ST, Sjöblom A, Nygårda T (2014) Observations of summer turbulent surface fluxes in a High Arctic fjord. Q J Roy Meteor Soc 140:666-675
Lee X, Massman W, Law B (2004) Handbook of micrometeorology. A guide for surface flux measurement and analysis. Kluwer Academic Publishers, Dordrecht, $250 \mathrm{pp}$

Lüers J, Bareiss J (2011) Direct near surface measurements of sensible heat fluxes in the arctic tundra applying eddy-covariance and laser scintillometry-The Arctic Turbulence Experiment 2006 on Svalbard (ARCTEX-2006). Theor Appl Climatol 105(3-4):387402

Łupikasza E (2013) Atmospheric precipitation. In: Marsz AA, Styszyńska A (eds) Climate and climate change at Hornsund, Svalbard. Gdynia Maritime University, Gdynia, pp. 199-211

Mahrt L (1998) Flux sampling errors for aircraft and towers. J Atmos Ocean Tech 15:416-429

Mäkiranta E, Vihma T, Sjöblom A, Tastula EM (2011) Observations and modelling of the atmospheric boundary layer over sea-ice in a Svalbard fjords. Bound-Layer Meteorol 140:105-123

Marsz AA (2013) Air temperature. In: Marsz AA, Styszyńska A (eds) Climate and climate change at Hornsund, Svalbard. Gdynia Maritime University, Gdynia, pp. 145-187

McFadden J, Chapin F, Hollinger D (1998) Subgrid-scale variability in the surface energy balance of arctic tundra. J Geophys Res-Atmos 103:28947-28961

Mirocha JD, Kosović B, Curry JA (2005) Vertical heat transfer in the lower atmosphere over the Arctic Ocean during clear-sky periods. Bound-Layer Meteorol 117:37-71

Nemitz E, Hargreaves KJ, McDonald AG, Dorsey JR, Fowler D (2002) Micrometeorological measurements of the urban heat budget and $\mathrm{CO} 2$ emissions on a city scale. Environ Sci Technol 36:3139-3146

Oechel W, Vourlitis G, Brooks S, Crawford T, Dumas E (1998) Intercomparison among chamber, tower, and aircraft net $\mathrm{CO} 2$ and energy fluxes measured during the Arctic System Science LandAtmosphere-Ice Interactions (ARCSS-LAII) Flux Study. J Geophys Res-Atmos 103:28993-29003

Pinto JO, Alam A, Maslanik JA, Curry JA, Stone RS (2003) Surface characteristics and atmospheric footprint of springtime Arctic leads at SHEBA. J Geophys Res-Oceans 108(C4):8051

Przybylak R (2002) Variability of air temperature and atmospheric precipitation in the Arctic. Atmospheric and Oceanographic Sciences Library 25, Kluwer Academic Publishers, Dordrecht/Boston/ London, $330 \mathrm{pp}$

Przybylak R (2003) The climate of the Arctic. Atmospheric and Oceanographic Sciences Library 26, Kluwer Academic Publishers, Dordrecht/Boston/London, $288 \mathrm{pp}$

Schotanus P, Nieuwstadt FTM, de Bruin HAR (1983) Temperature measurement with a sonic anemometer and its application to heat and moisture fluctuations. Bound-Layer Meteorol 26:81-93

Sjöblom A (2014) Turbulent fluxes of momentum and heat over land in the high-Arctic summer: the influence of observation techniques. Polar Res 33:21567. doi:10.3402/polar.v33.21567

Skogseth R, Smedsrud LH, Nilsen F, Fer I (2008) Observations of hydrography and downflow of brine- enriched shelf water in the Storfjorden polynya, Svalbard. J Geophys Res 113:C08049. doi: 10.1029/2007JC004452

Styszyńska A (2013) Results of observations. In: Marsz AA, Styszyńska A (eds) Climate and climate change at Hornsund, Svalbard. Gdynia Maritime University, Gdynia, pp. 321-365

Swinbank WC (1951) The measurement of vertical transfer of heat and water vapor by eddies in the lower atmosphere. J Meteorol 8:135145

Uttal T, Curry JA, McPhee MG, Perovich DK, Moritz RE, Maslanik JA, Guest PS, Stern HL, Moore JA, Turenne R, Heiberg A, Serreze MC, Wylie DP, Persson POG, Paulson CA, Halle C, Morison JH, Wheeler PA, Makshtas A, Welch H, Shupe MD, Intrieri JM, Stamnes K, Lindsey RW, Pinkel R, Pegau WS, Stanton TP, 
Grenfeld TC (2002) Surface heat budget of the Arctic Ocean. B Am Meteorol Soc 83:255-275

van Dijk A, Kohsiek W, de Bruin HA (2003) Oxygen sensitivity of krypton and Lymann-hygrometers. J Atmos Ocean Tech 20:143-151

Vickers D, Mahrt L (1997) Quality control and flux sampling problems for tower and aircraft data. J Atmos Ocean Tech 14:512-526
Webb EK, Pearman GI, Leuning R (1980) Correction of the flux measurements for density effects due to heat and water vapour transfer. Q J Roy Meteor Soc 106:85-100

Westermann S, Lüers J, Langer M, Boike J (2009) The annual surface energy budget of a high-Arctic permafrost site on Svalbard, Norway. Cryosphere 3:345-263 